\title{
Synergistic Effect of Temperature and Ultrasonic Field on Seawater Modification of Wheat Straw Fibers
}

\author{
Liangpeng Jiang, * Hao Wang, Yue Kong, and Lihong Liu \\ This study investigated the synergistic effect of temperature and ultrasonic \\ field on seawater modification of wheat straw fibers via orthogonal design. \\ Based on orthogonal results, physicochemical and thermal properties of \\ wheat straw fibers were also reported. The results indicated that a $120 \mathrm{~min}$ \\ seawater modification of the fibers at a $70^{\circ} \mathrm{C}$ heating temperature and 90 \\ $\mathrm{W}$ ultrasonic power increased water absorption. The increase was \\ attributable to the removal of the waxy layer and non-cellulosic materials, \\ which, in turn, decreased the silicon elemental content and hydrogen \\ bonding, as well as increased surface roughness, crystallinity, and thermal \\ stability. The physicochemical and thermal characterization showed that \\ this modification method has potential to be a viable industrial application.
}

Keywords: Wheat straw fibers; Seawater modification; Temperature field; Ultrasonic field; Synergistic effect

Contact information: School of Mechanical Engineering, Anhui University of Science and Technology, Huainan 232001, China; *Corresponding author: jianglp98@outlook.com

\section{INTRODUCTION}

Surface modification of lignocellulosic fibers is an essential link for their emerging use as a reinforced material in the preparation of wood-plastic composites. The reason for this is that the hydrophilic nature of fiber surfaces results in a poor compatibility with hydrophobic polymers (Väisänen et al. 2016). Chemical modification of lignocellulosic fibers helps remove surface impurities and can reduce their hydrophilicity, while increasing their fiber-polymer interfacial compatibility (Siakeng et al. 2019). However, the problems encountered in chemical modification use originate from their negative impact on the environment and human health (Koohestani et al. 2019).

Physical modifications such as steam (Brugnago et al. 2011; Brito et al. 2020) and hydrothermal (Qian et al. 2015; Liu et al. 2016), physical field-assisted chemical modification such as steam-assisted alkali (Saha et al. 2010) and ultrasonic-assisted alkali (Krishnaiah et al. 2017), and many biological modifications represented by enzyme and seawater have been suggested for their potential to replace pure chemical modification. Among these, seawater modification is a relatively novel area of study, and related reports have rarely been published (Rashid et al. 2017a,b; Agrebi et al. 2018). Seawater, due to its high salinity and weak alkalinity, helps remove the outer layer of hemicellulose, wax, and pectin. This layer protects the fiber from the weather degradation; however, it causes poor fiber-polymer interfacial compatibility. Rashid et al. (2016 and 2017c) report that seawater modification could affect the characterization of sugar palm and improve the fiber-polymer interfacial compatibility.

Based on preliminary experiments, the efficacy of seawater modification further increases at elevated temperatures and ultrasonic power because heat and ultrasonic energy 
provides additional help in breaking the hydrogen bonds between fibrils. However, there has been no report on physical field-assisted seawater treatment to modify lignocellulosic fibers. Given this, seawater modification of lignocellulosic fibers from wheat straw in the co-presence of temperature and ultrasonic field has been investigated in this study.

\section{EXPERIMENTAL}

\section{Materials}

Wheat straw fibers (WSFs) were obtained from a cropland in Huainan, China. The fibers were washed with tap water and air-dried at $25 \pm 5{ }^{\circ} \mathrm{C}$ until reaching a constant weight. Simulated seawater was prepared according to ASTM D1141-1998 (2013). Detail components of the simulated seawater is summarized in Table 1.

Table 1. Detailed Components of Simulated Seawater

\begin{tabular}{|c|c|c|c|c|c|}
\hline Component & $\mathrm{NaCl}$ & $\mathrm{MgCl}_{2}$ & $\mathrm{Na}_{2} \mathrm{SO}_{4}$ & $\mathrm{CaCl}_{2}$ & $\mathrm{KCl}$ \\
\hline Concentration $\left(\mathrm{g} \cdot \mathrm{L}^{-1}\right)$ & 24.53 & 5.20 & 4.09 & 1.16 & 0.695 \\
\hline Component & $\mathrm{NaHCO}_{3}$ & $\mathrm{KBr}$ & $\mathrm{H}_{3} \mathrm{BO}_{3}$ & $\mathrm{SrCl}_{2}$ & $\mathrm{NaF}$ \\
\hline Concentration $\left(\mathrm{g} \cdot \mathrm{L}^{-1}\right)$ & 0.201 & 0.101 & 0.027 & 0.025 & 0.003 \\
\hline
\end{tabular}

\section{Orthogonal design}

The orthogonal design factor-level and scheme-results are listed in Tables 2 and 3, respectively. As shown, the WSFs were immersed in simulated seawater (1:300 solidliquid mass ratio) at given time $\left(\mathrm{X}_{1}\right)$, heating temperature $\left(\mathrm{X}_{2}\right)$, and ultrasonic power $\left(\mathrm{X}_{3}\right)$. After modification, the fibers were rinsed with distilled water and oven-dried at $90{ }^{\circ} \mathrm{C}$ for $12 \mathrm{~h}$. Water absorption of the WSFs was used as the basis for assessing the modification effect. See the Methods section for more details about water absorption.

Table 2. Factor-level of Orthogonal Design

\begin{tabular}{|c|c|c|c|c|c|}
\hline \multirow{2}{*}{ Factors } & \multirow{2}{*}{ Units } & \multicolumn{4}{|c|}{ Levels } \\
\cline { 3 - 6 } & & 1 & 2 & 3 & 4 \\
\hline $\mathrm{X}_{1}$ & $\min$ & 60 & 80 & 100 & 120 \\
\hline $\mathrm{X}_{2}$ & ${ }^{\circ} \mathrm{C}$ & 40 & 50 & 60 & 70 \\
\hline $\mathrm{X}_{3}$ & $\mathrm{~W}$ & 70 & 80 & 90 & 100 \\
\hline
\end{tabular}


Table 3. Scheme-results of Orthogonal Design

\begin{tabular}{|c|c|c|c|c|}
\hline Test No. & $\mathrm{X}_{1}$ & $\mathrm{X}_{2}$ & $\mathrm{X}_{3}$ & Water Absorption (\%) \\
\hline $\mathrm{T}_{1}$ & 1 & 1 & 1 & $171.3 \pm 7.0$ \\
\hline $\mathrm{T}_{2}$ & 1 & 2 & 2 & $166.4 \pm 3.1$ \\
\hline $\mathrm{T}_{3}$ & 1 & 3 & 3 & $182.0 \pm 6.8$ \\
\hline $\mathrm{T}_{4}$ & 1 & 4 & 4 & $191.2 \pm 6.9$ \\
\hline $\mathrm{T}_{5}$ & 2 & 1 & 2 & $175.0 \pm 6.2$ \\
\hline $\mathrm{T}_{6}$ & 2 & 2 & 1 & $188.0 \pm 5.8$ \\
\hline $\mathrm{T}_{7}$ & 2 & 3 & 4 & $184.1 \pm 4.9$ \\
\hline $\mathrm{T}_{8}$ & 2 & 4 & 3 & $198.6 \pm 8.7$ \\
\hline $\mathrm{T}_{9}$ & 3 & 1 & 3 & $197.3 \pm 4.4$ \\
\hline $\mathrm{T}_{10}$ & 3 & 2 & 4 & $183.9 \pm 3.4$ \\
\hline $\mathrm{T}_{11}$ & 3 & 3 & 1 & $186.3 \pm 8.5$ \\
\hline $\mathrm{T}_{12}$ & 3 & 4 & 2 & $199.3 \pm 7.4$ \\
\hline $\mathrm{T}_{13}$ & 4 & 1 & 4 & $203.6 \pm 3.9$ \\
\hline $\mathrm{T}_{14}$ & 4 & 2 & 3 & $223.2 \pm 6.3$ \\
\hline $\mathrm{T}_{15}$ & 4 & 3 & 2 & $209.8 \pm 4.5$ \\
\hline $\mathrm{T}_{16}$ & 4 & 4 & 1 & $218.6 \pm 8.3$ \\
\hline
\end{tabular}

\section{Methods}

Water absorption

The WSFs were oven-dried at $90{ }^{\circ} \mathrm{C}$ for $12 \mathrm{~h}$ to a constant weight $\left(m_{1}\right)$ and then immersed in distilled water for $24 \mathrm{~h}$ at $20^{\circ} \mathrm{C}$ to a certain weight $\left(m_{2}\right)$. Six samples were tested, and at least five replicate samples were presented as an average of the tested samples. The water absorption (WA) was calculated from Eq. 1:

$$
W A=\left(m_{2}-m_{1}\right) / m_{a} \times 100
$$

Scanning electron microscopy (SEM) and energy dispersive spectroscopy (EDS)

The topography and element of external WSFs surfaces were detected using a FlexSEM 1000 SEM (Hitachi Ltd., Tokyo, Japan) equipped with 550i EDS (IXRF Ltd., Austin, USA). Prior to the test, the samples were gold sputtered to avoid poor image resolution.

Fourier Transform Infrared (FTIR) and x-ray diffraction (XRD)

The FTIR spectra of the WSFs were collected with a Nicolet iS10 FTIR spectrometer (Thermo Fisher Scientific Co., Ltd., Shanghai, China). The wavenumber range was taken from $1000 \mathrm{~cm}^{-1}$ to $4000 \mathrm{~cm}^{-1}$ and at $4 \mathrm{~cm}^{-1}$ resolutions.

The XRD spectra of the WSFs were collected by X'Pert PRO X-ray diffractometer (PANalytical B.V., Almelo, Netherlands). A $2 \theta$ range was taken from $10^{\circ}$ to $60^{\circ}$ and at a speed of $0.33^{\circ} \cdot \mathrm{min}^{-1}$. The crystallinity index $(\mathrm{Cr} I)$ was calculated according to Eq. 2 ,

$$
\operatorname{CrI}=\left[1-\left(I_{a m} / I_{002}\right)\right] \times 100
$$

where $I_{a m}$ and $I_{002}$ are the maximum intensities at $2 \theta=18^{\circ}$ and $22.5^{\circ}$, respectively.

Thermogravimetry $(T G)$ and derivative thermal gravity (DTG)

The TG and DTG curves of the WSFs were collected by a STA 449 F3 synchronized thermal analyzer (NETZSCH Scientific Instrument Trading Co., Ltd., Selb, 
Germany). The temperature range was taken from $30{ }^{\circ} \mathrm{C}$ to $800{ }^{\circ} \mathrm{C}$ and at $20{ }^{\circ} \mathrm{C} \cdot \mathrm{min}^{-1}$ heating rates. All tests were made under an argon atmosphere.

\section{RESULTS AND DISCUSSION}

\section{Variance and Mean-standard Deviation Analysis}

The results of variance and mean-standard deviation analyses are listed in Tables 4 and 5 , respectively. When the P-value was less than 0.05 , a factor was considered to have a significant effect on the test results. The P-values listed in Table 4 show that the effect of $\mathrm{X}_{1}$ and $\mathrm{X}_{2}$ (except for $\mathrm{X}_{3}$ ) on water absorption were significant, which indicated that the selected levels in the orthogonal design were reasonable. The rankings of the significance for the three factors were: $X_{1}>X_{2}>X_{3}$.

Water absorption of the WSFs was improved because through seawater modification (water absorption of the unmodified WSFs was 139.3\%), the wax layer with high water resistance and the non-cellulosic material (hemicellulose and lignin) of the fibers decreased, and the water permeability in the fibers improved. Therefore, a higher water absorption corresponded to a better modification effect. According to the mathematical statistics listed in Table 5, the theoretical combination for highest water absorption was $\mathrm{X}_{14} \mathrm{X}_{24} \mathrm{X}_{33}$.

Table 4. Variance Analysis of Orthogonal Design

\begin{tabular}{|c|c|c|c|c|c|}
\hline Source & Type-III Sum of Squares & DF & Mean Square & F-value & P-value \\
\hline $\mathrm{X}_{1}$ & 2835.3 & 3 & 945.1 & 30.0 & 0.001 \\
\hline $\mathrm{X}_{2}$ & 517.4 & 3 & 172.5 & 5.5 & 0.037 \\
\hline $\mathrm{X}_{3}$ & 358.9 & 3 & 119.7 & 3.8 & 0.077 \\
\hline Error & 189.0 & 6 & 31.5 & & \\
\hline Total & 596225.2 & 16 & & & \\
\hline
\end{tabular}

Table 5. Mean-standard Deviation of Orthogonal Design

\begin{tabular}{|c|c|c|c|}
\hline Code & $\mathrm{X}_{1}$ & $\mathrm{X}_{2}$ & $\mathrm{X}_{3}$ \\
\hline Level 1 & $177.7 \pm 11.1^{\mathrm{c}}$ & $186.8 \pm 16.1^{\mathrm{b}}$ & $191.0 \pm 19.8^{\mathrm{ab}}$ \\
\hline Level 2 & $186.4 \pm 9.8^{\mathrm{bc}}$ & $190.4 \pm 23.8^{\mathrm{b}}$ & $187.6 \pm 20.3^{\mathrm{b}}$ \\
\hline Level 3 & $191.7 \pm 7.7^{\mathrm{b}}$ & $190.6 \pm 12.9^{\mathrm{b}}$ & $200.3 \pm 17.0^{\mathrm{a}}$ \\
\hline Level 4 & $213.8 \pm 8.8^{\mathrm{a}}$ & $201.9 \pm 11.7^{\mathrm{a}}$ & $190.7 \pm 9.2^{\mathrm{ab}}$ \\
\hline
\end{tabular}

\section{SEM and EDS Analysis}

An increase in surface roughness is very important to improve the mechanical and thermal properties of wood-plastic composites (Krishnaiah et al. 2017). Figures 1 and 2 compare SEM images and EDS spectra of the external surfaces of both unmodified and modified WSFs, respectively. Figure 1a displays the external surfaces of unmodified WSFs were smooth with a clear wax layer, which resulted in a poor mechanical interlocking between the fiber surface and polymer matrix. Figure $1 \mathrm{~b}$ indicates that when WSFs were modified through exposure to seawater at a $70{ }^{\circ} \mathrm{C}$ heating temperature and a $90 \mathrm{~W}$ ultrasonic power for $120 \mathrm{~min}$, the surface roughness of the fibers increased and the fibrils were found on the external surface, which contributed to the increased contact area and interlock strength between the fiber surface and polymer matrix.

The wax layer on the external WSFs surfaces was mainly composed of silicon 
dioxide $\left(\mathrm{SiO}_{2}\right)$. Silicon $(\mathrm{Si})$ has high heat resistance and plays a key role in defining the thermal stability of lignocellulosic fibers. Compared to unmodified WSFs, WSFs modified at $70{ }^{\circ} \mathrm{C}$ and $90 \mathrm{~W}$ for $120 \mathrm{~min}$ showed a $94.3 \%$ decrease in the weight percentage of $\mathrm{Si}$ due to the wax layer removal. The effect of Si levels on the thermal stability of the WSFs was discussed in depth during the TG and DTG analyses.

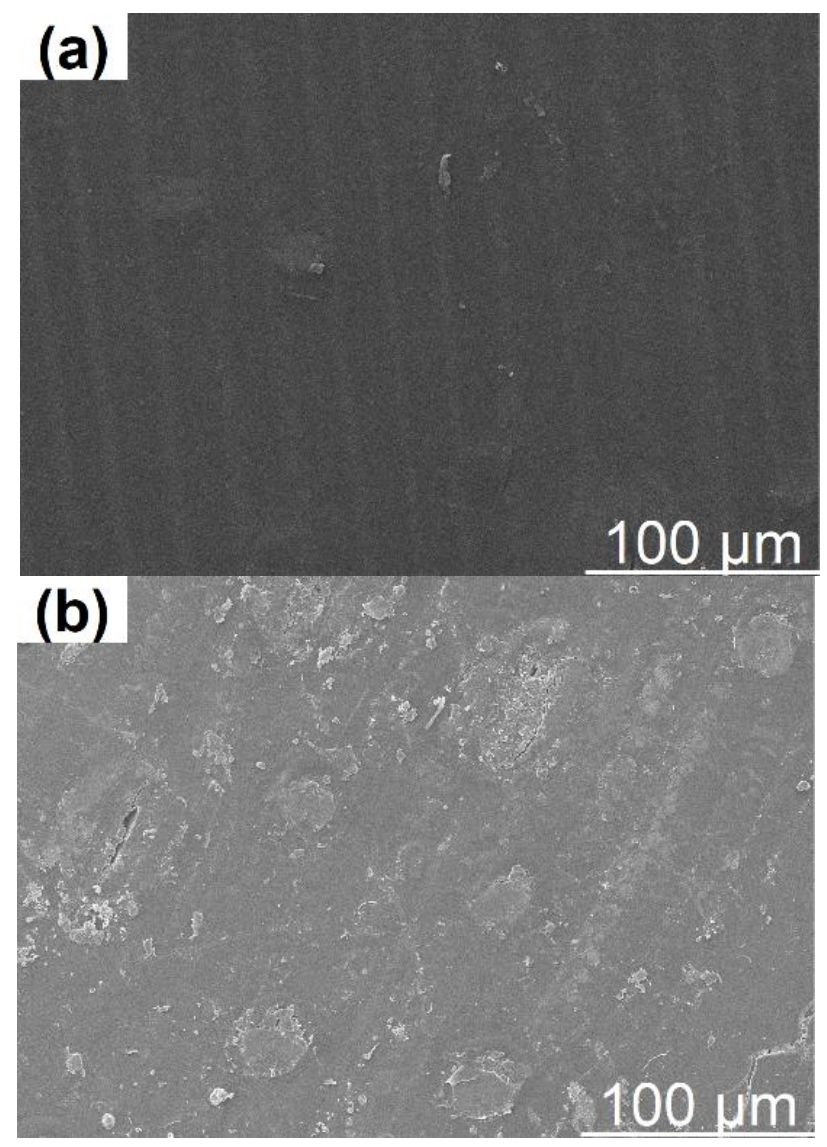

Fig. 1. SEM images of external surface of WSFs: (a) unmodified, (b) modified

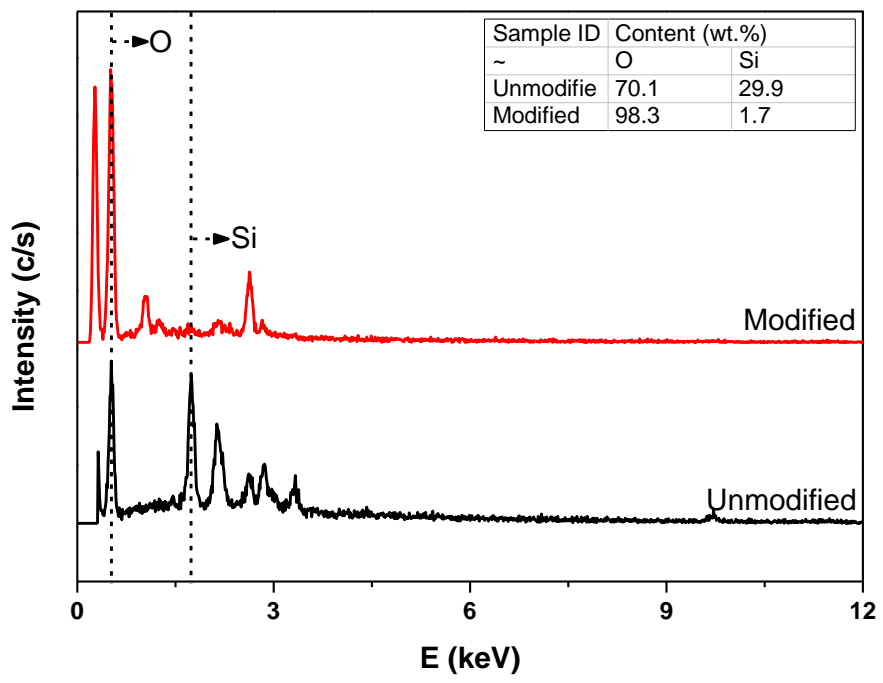

Fig. 2. EDS spectra of external WSFs surfaces 


\section{FTIR and XRD Analysis}

Lignocellulosic fibers are mainly composed of cellulose, hemicellulose, and lignin. Holocellulose (cellulose and hemicellulose) is responsible for moisture absorption because both cellulose and hemicellulose are rich with hydroxyl groups. Moisture absorption leads to a reduction in mechanical properties of lignocellulosic fibers. Figures 3 and 4 compare the FTIR and XRD spectra of both unmodified and modified WSFs, respectively. The peak at the $3500 \mathrm{~cm}^{-1}$ to $3300 \mathrm{~cm}^{-1}$ range is characteristic for $\mathrm{O}-\mathrm{H}$ stretching in hydroxyl groups (Jiang et al. 2017). The intensity reduction of $\mathrm{O}-\mathrm{H}$ stretching after seawater modification at $70{ }^{\circ} \mathrm{C}$ and $90 \mathrm{~W}$ for 120 min indicated a breakage of hydrogen bonds between hydroxyl groups of cellulose and hemicellulose. The peak at the $1735 \mathrm{~cm}^{-1}$ to $1700 \mathrm{~cm}^{-1}$ range corresponded to $\mathrm{C}=\mathrm{O}$ stretching in hemicellulose and lignin which was weakened slightly following modification and indicated the removal of non-crystalline materials (hemicellulose and lignin) (Pereira et al. 2019). This finding is in good agreement with the results reported by Rashid et al. (2016).

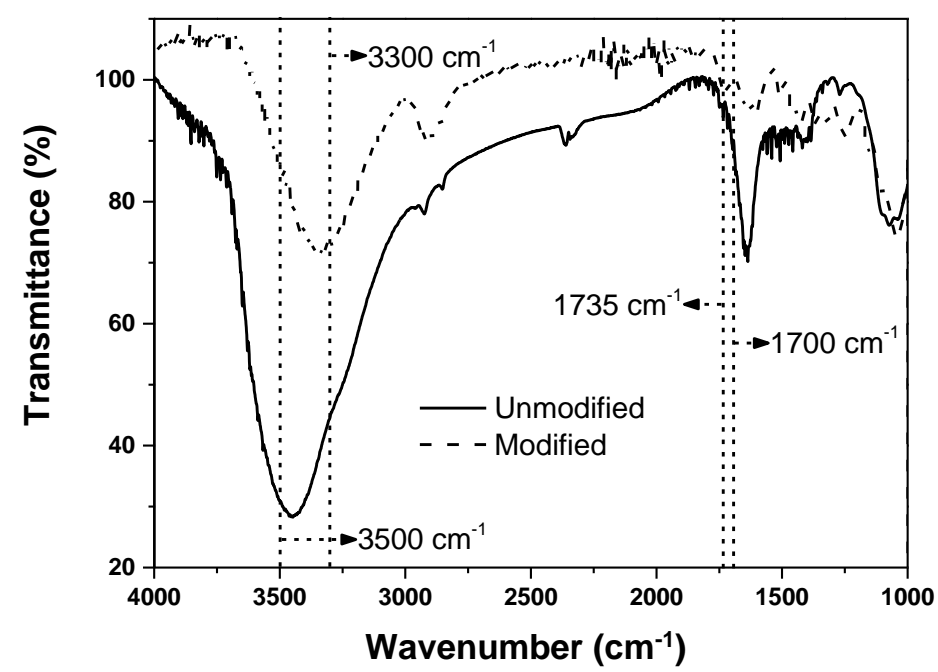

Fig. 3. FTIR spectra of WSFs

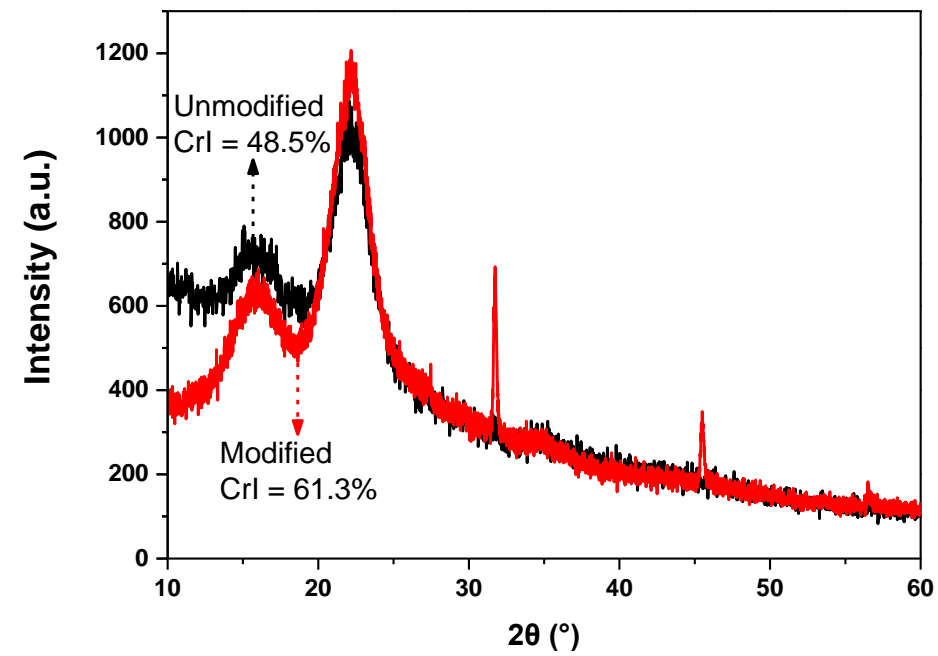

Fig. 4. XRD spectra of WSFs 
The crystallinity of the seawater modified WSFs at $70{ }^{\circ} \mathrm{C}$ and $90 \mathrm{~W}$ for $120 \mathrm{~min}$ was increased to $61.3 \%$ from $48.5 \%$. The unmodified WSFs showed an increase in amplitude by $26.4 \%$ because the modification removed non-crystalline materials in the fiber bundles and allowed the cellulose fibers freedom to adopt a more crystalline structure.

\section{TG and DTG Analysis}

Figure 5 and Table 6 show that when the temperature increased to $800{ }^{\circ} \mathrm{C}$ from 30 ${ }^{\circ} \mathrm{C}$, the pyrolysis of the WSFs underwent two main weight loss stages and three noticeably endothermic peaks. The first weight loss stage and endothermic peak I were in the $30{ }^{\circ} \mathrm{C}$ to $150{ }^{\circ} \mathrm{C}$ temperature range, which was due to moisture evaporation. The second weight loss stage and endothermic peaks II and III were in the $150{ }^{\circ} \mathrm{C}$ to $800{ }^{\circ} \mathrm{C}$ temperature range, which was due to hemicellulose degradation $\left(150{ }^{\circ} \mathrm{C}\right.$ to $350{ }^{\circ} \mathrm{C}$ corresponded to endothermic peak II), cellulose $\left(275^{\circ} \mathrm{C}\right.$ to $350{ }^{\circ} \mathrm{C}$ corresponded to endothermic peak III), and lignin $\left(250{ }^{\circ} \mathrm{C}\right.$ to $\left.500{ }^{\circ} \mathrm{C}\right)$ (Jiang et al. 2019). The endothermic peak of lignin could not be observed due to low weight loss rate and wide pyrolysis temperature range.

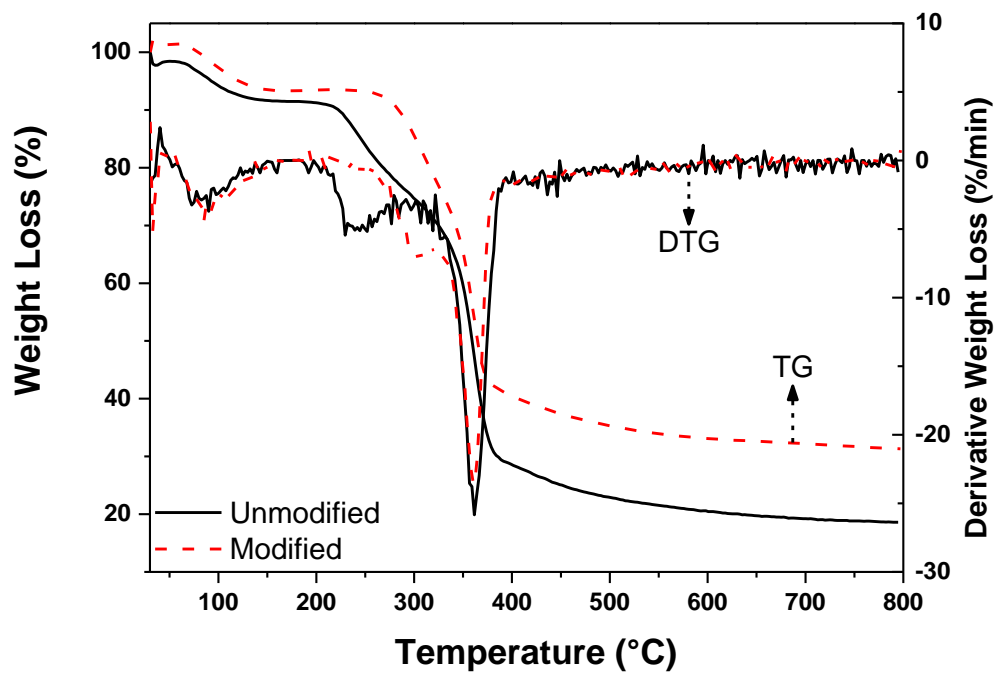

Fig. 5. TG and DTG curves of WSFs

Table 6. Pyrolysis Characteristic Data of WSFs

\begin{tabular}{|c|c|c|c|c|}
\hline \multirow{2}{*}{ Sample ID } & \multirow{2}{*}{$T_{5 \%}\left({ }^{\circ} \mathrm{C}\right)$} & Peak I & Peak II & Peak III \\
\cline { 3 - 5 } & 96.0 & $T\left({ }^{\circ} \mathrm{C}\right)$ & $T\left({ }^{\circ} \mathrm{C}\right)$ & $T\left({ }^{\circ} \mathrm{C}\right)$ \\
\hline Unmodified & 96.8 & 93.8 & 293.1 & 365.0 \\
\hline Modified & 114.0 & 78.3 & 222.4 & 355.6 \\
\hline
\end{tabular}

Compared to the unmodified WSFs, the WSFs exposed to seawater at $70{ }^{\circ} \mathrm{C}$ and 90 $\mathrm{W}$ for 120 min showed a lower temperature at endothermic peaks II and III. The reason can be explained from the perspectives of the reduction in Si with high heat resistance. The pyrolysis temperature of the lignocellulosic fiber at 5\% weight loss $\left(T_{5} \%\right)$ can be used as the basis for assessing thermal stability (Yusriah et al. 2014). Clearly, the modified WSFs exhibited higher thermal stability compared to the unmodified WSFs, which can be explained by the reduction in hemicellulose with low heat resistance. 


\section{Comparison of Three Types of Seawater Modifications}

In a preliminary experiment, the optimum parameters for physical field-assisted seawater modification without regard to synergistic effect of temperature and ultrasonic fields were $82.2^{\circ} \mathrm{C}+53.0 \mathrm{~min}$ and $80.0 \mathrm{~W}+49.0 \mathrm{~min}$, respectively. By comparison, the WSFs exposed to seawater at $70{ }^{\circ} \mathrm{C}$ and $90 \mathrm{~W}$ for $120 \mathrm{~min}$ had a lower Si level, higher crystallinity, and higher thermal stability than any other type of seawater modification listed in Table 7, which indicated a better modification effect.

Table 7. Comparison of Three Types of Seawater Modifications

\begin{tabular}{|c|c|c|c|}
\hline Modification Parameters & Si Level (wt\%) & $\mathrm{Crl}(\%)$ & $T_{5 \%}\left({ }^{\circ} \mathrm{C}\right)$ \\
\hline $70{ }^{\circ} \mathrm{C}+90 \mathrm{~W}+120 \mathrm{~min}$ & 1.7 & 61.3 & 114.0 \\
\hline $82 .{ }^{\circ} \mathrm{C}+53.0 \mathrm{~min}$ & 11.5 & 51.1 & 106.0 \\
\hline $80.0 \mathrm{~W}+49.0 \mathrm{~min}$ & 24.8 & 50.7 & 100.0 \\
\hline
\end{tabular}

\section{CONCLUSIONS}

1. The processing time had the most significant effect on the water absorption, followed by the heating temperature and the ultrasonic power. A 120 min processing time, a 70 ${ }^{\circ} \mathrm{C}$ heating temperature, and a $90 \mathrm{~W}$ ultrasonic power were determined as the optimum combinations.

2. When exposed to seawater at $70{ }^{\circ} \mathrm{C}$ and $90 \mathrm{~W}$ for $120 \mathrm{~min}$, the level of Si element and the hydrogen bond of the WSFs decreased. However, the surface roughness, crystallinity, and thermal stability of the WSFs increased. These changes are beneficial to the preparation of wood-plastic composites.

3. For an ultrasonic device equipped with a heating function, the operation for increasing water temperature and ultrasonic power is simple and rapid, and the energy cost is relatively low. Therefore, temperature and ultrasonic field-assisted seawater can be considered as a modification method worth promoting.

\section{ACKNOWLEDGEMENTS}

This work was supported by the Natural Science Foundation of the Higher Education Institutions of Anhui Province, Grant. No. KJ2020A0283.

\section{REFERENCES CITED}

Agrebi, F., Ghorbel, N., Rashid, B., Kallel, A., and Jawaid, M. (2018). "Influence of treatments on the dielectric properties of sugar palm fiber reinforced phenolic composites," Journal of Molecular Liquids 263, 342-348. DOI:

10.1016/j.molliq.2018.04.130

ASTM D1141-1998 (2013). "Standard practice for the preparation of substitute ocean water," ASTM International, West Conshohocken, USA.

Brugnago, R. J., Satyanarayana, K. G., Wypych, F., and Ramos, L. P. (2011). “The effect of steam explosion on the production of sugarcane bagasse/polyester composites," 
Composites Part A: Applied Science and Manufacturing 42(4), 364-370. DOI: 10.1016/j.compositesa.2010.12.009

Brito, E. B. D., Tienne, L. G. P., Cordeiro, S. B., Marques, M. D. F. V., and Monteiro, S. N. (2020). "The influence of steam explosion treatment of green coffee cake on the thermal and mechanical properties of reinforced polypropylene matrix composites," Journal of Materials Research and Technology 9(3), 4051-4060. DOI: 10.1016/j.jmrt.2020.02.032

Jiang, L., He, C., Fu, J., and Chen, D. (2017). "Wear behavior of straw fiber-reinforced polyvinyl chloride composites under simulated acid rain conditions," Polymer Testing 62, 373-381. DOI: 10.1016/j.polymertesting.2017.07.028

Jiang, L., He, C., Fu, J., and Xu, D. (2019). "Enhancement of wear and corrosion resistance of polyvinyl chloride/sorghum straw-based composites in cyclic sea water and acid rain conditions," Construction and Building Materials 223, 133-141. DOI: 10.1016/j.conbuildmat.2019.06.216

Koohestani, B., Darban, A. K., Mokhtari, P., Yilmaz, E., and Darezereshki, E. (2019). "Comparison of different natural fiber treatments: A literature review," International Journal of Environmental Science and Technology 16, 629-642. DOI: 10.1007/s13762-018-1890-9

Krishnaiah, P., Ratnam, C. T., and Manickam, S. (2017). "Enhancements in crystallinity, thermal stability, tensile modulus and strength of sisal fibres and their PP composites induced by the synergistic effects of alkali and high intensity ultrasound (HIU) treatments," Ultrasonics Sonochemistry 34, 729-742. DOI: 10.1016/j.ultsonch.2016.07.008

Liu, M., Silva, D. A. S., Fernando, D., Meyer, A. S., Madsen, B., Daniel, G., and Thygesen, A. (2016). "Controlled retting of hemp fibres: Effect of hydrothermal pretreatment and enzymatic retting on the mechanical properties of unidirectional hemp/epoxy composites," Composites Part A: Applied Science and Manufacturing 88, 253-262. DOI: 10.1016/j.compositesa.2016.06.003

Pereira, J. F., Ferreira D. P., Bessa, J., Matos, J., Cunha, F., Araújo, I., Silva, L. F., Pinho, E., and Fangueiro, R. (2019). "Mechanical performance of thermoplastic olefin composites reinforced with coir and sisal natural fibers: Influence of surface pretreatment," Polymer Composites 40(9), 3472-3481. DOI: 10.1002/pc.25209

Qian, S., Wang, H., Zarei, E., and Sheng, K. (2015). "Effect of hydrothermal pretreatment on the properties of moso bamboo particles reinforced polyvinyl chloride composites," Composites Part B: Engineering 82, 23-29. DOI: 10.1016/j.compositesb.2015.08.007

Rashid, B., Leman, Z., Jawaid, M., Ghazali, M. J., and Ishak, M. R. (2016). "Physicochemical and thermal properties of lignocellulosic fiber from sugar palm fibers: Effect of treatment," Cellulose 23, 2905-2916. DOI: 10.1007/s10570-0161005-Z

Rashid, B., Leman, Z., Jawaid, M., Ghazali, M. J., and Ishak, M. R. (2017a). "Effect of treatments on the physical and morphological properties of SPF/phenolic composites," Journal of Natural Fibers 14(5), 645-657. DOI: 10.1080/15440478.2016.1266291

Rashid, B., Leman, Z., Jawaid, M., Ghazali, M. J., and Ishak, M. R. (2017b). "Influence of treatments on the mechanical and thermal properties of sugar palm fibre reinforced phenolic composites," BioResources 12(1), 1447-1462. DOI: 
10.15376/biores.12.1.1447-1462

Rashid, B., Leman, Z., Jawaid, M., Ghazali, M. J., Ishak, M. R., Abdelgnei, M. A. (2017c). "Dry sliding wear behavior of untreated and treated sugar palm fiber filled phenolic composites using factorial technique," Wear 380-381, 26-35. DOI: 10.1016/j.wear.2017.03.011

Saha, P., Manna, S., Chowdhury, S. R., Sen, R., Roy, D., and Adhikari, B. (2010). "Enhancement of tensile strength of lignocellulosic jute fibers by alkali-steam treatment," Bioresource Technology 101(9), 3182-3187. DOI: 10.1016/j.biortech.2009.12.010

Siakeng, R., Jawaid, M., Ariffin, H., Sapuan, S. M., Asim, M., and Saba, N. (2019). "Natural fiber reinforced polylactic acid composites: A review," Polymer Composites 40(2), 446-463. DOI: 10.1002/pc.24747

Väisänen, T., Haapala, A., Lappalainen, R., and Tomppo, L. (2016). "Utilization of agricultural and forest industry waste and residues in natural fiber-polymer composites: A review," Waste Management 54, 62-73. DOI: 10.1016/j.wasman.2016.04.037

Yusriah, L., Sapuan, S. M., Zainudin, E. S., and Mariatti, M. (2014). "Characterization of physical, mechanical, thermal and morphological properties of agro-waste betel nut (Areca catechu) husk fibre," Journal of Cleaner Production 72, 174-180. DOI: 10.1016/j.jclepro.2014.02.025

Article submitted: December 10, 2020; Peer review completed: February 6, 2021; Revised version received and accepted: February 10, 2021; Published: February 12, 2021 DOI: 10.15376/biores.16.2.2503-2512 